Artigos

Volume 9 - 2019|n. 22

\title{
O Piso Salarial Nacional no Contexto do Financiamento da Educação no Brasil: limites e possibilidades do seu cumprimento
}

\author{
Eliara Cristina Nogueira da Silva Teixeira \\ Secretaria da Educação do Estado da Bahia (SEC/BA), Pindaí/BA - Brasil \\ Claudio Pinto Nunes \\ Universidade Estadual do Sudoeste da Bahia (UESB), Vitória da Conquista/BA - Brasil
}

\section{Resumo}

O artigo versa sobre o financiamento da educação no Brasil e objetiva propiciar a compreensão de que políticas públicas implantadas no País e novas ações a serem implementadas necessitam ser sustentadas em uma base sólida de financiamento. O Piso Salarial Nacional é um exemplo de política que necessita de aporte financeiro para ter sustentação, pois, desde a sua promulgação, as justificativas dadas pelos entes federados para o seu não cumprimento esbarram na impossibilidade financeira. Depreende-se da pesquisa realizada que a ampliação de recursos a serem investidos nesse setor social é uma necessidade urgente e implica: aporte de novos recursos financeiros; elevação para $10 \%$ do percentual do PIB a ser investido na educação; execução da meta 20 do novo PNE e, principalmente, da meta 17, de modo a alcançar o efetivo cumprimento da Lei do PSPN.

Palavras-chave: Financiamento da educação. Piso Salarial Nacional Docente. Aporte de Novos Recursos Financeiros.

\section{The National Wage Floor in the Context of Education Funding in}

\section{Brazil: limits and possibilities of compliance}

\begin{abstract}
This article addresses the funding of education in Brazil, aiming to provide the understanding that the public policies implemented in the country, and new actions to be established, need to be sustained on a sound basis of how they can be financed. The National Wage Floor is an example of a policy that needs financial support, since from its promulgation the justifications given by the federated entities for their non-fulfillment are based on financial impossibility. It appears from the research that the increase of resources to be invested in this social sector is an urgent need and implies: the contribution of new financial resources; an increase to $10 \%$ of the GDP to be invested in education; implementation of goal 20 of the new National Education Plan and, especially, goal 17, in order to achieve effective compliance with the National Wage Floor legislation.
\end{abstract}

Keywords: Education Funding. Teaching National Wage Floor. Contribution of New Financial Resources. 
O Piso Salarial Nacional no Contexto do Financiamento da Educação no Brasil

\section{Introdução}

No Brasil, a ideia de educação como uma obrigação, garantida efetivamente à população, aparece desde o Império, quando algumas Províncias declararam a obrigatoriedade do ensino primário. A questão do direito à educação também se fez presente nas diversas Constituições do País e a gratuidade, que aparece na Constituição Federal de 1824, colocou o Brasil entre os primeiros países do mundo em que a educação gratuita é prevista na legislação, mas sem, no entanto, ser efetivamente transformada em política pública e garantida de fato à população. De forma mais abrangente ou restrita, as diversas Constituições brasileiras sempre fizeram referências à educação, mas é na Carta Magna de 1988 que a questão do direito à educação e a obrigatoriedade e gratuidade do ensino aparecem de forma mais ampla, a saber, nos artigos $6^{\circ}, 205$ e 208. Todavia, para a garantia da oferta do ensino público gratuito e de qualidade para todo e qualquer cidadão brasileiro, faz-se necessário contar com a disponibilidade de recursos públicos suficientes para dar sustentação às diversas políticas públicas educacionais e, na história da educação brasileira, nem sempre o poder público no Brasil enxergou a educação como um direito social que se coadune com o pleno exercício da cidadania.

Com a questão salarial do professor, o descaso e/ou a desresponsabilização do Estado brasileiro não foi diferente. Foram quase dois séculos de desvalorização para se chegar à Lei do Piso Salarial Profissional Nacional, que é uma conquista resultante das mais emblemáticas lutas dos profissionais da educação básica brasileira na busca pelo reconhecimento social da profissão docente e pela isonomia salarial. Porém, embora ela tenha sido sancionada há quase uma década, não encontrou o aporte de recursos necessários à sua efetivação, o que tem provocado descontentamento aos educadores e embates entre estes e o poder público.

Assim, neste trabalho, que é resultado de um estudo de natureza exploratória de cunho bibliográfico e documental, debate-se a questão do financiamento da educação no Brasil, sua incorporação na legislação brasileira e a sua vinculação direta quando discutimos direito à educação, qualidade do ensino, carreira e salário docente. Também se discute sobre a Política de Fundos (Fundef e Fundeb) e a complexa sistemática de redistribuição de recursos entre municípios e estados, a complementação da União, os limites e possibilidades de sustentação do Piso salarial docente; e finaliza destacando a vinculação dos recursos aplicados em educação a um percentual do Produto Interno Bruto (PIB) e a sua relação com o futuro da educação brasileira e com o efetivo cumprimento do piso salarial nacional atualmente.

\section{O salário docente no contexto do financiamento da Educação no Brasil}

Nos primeiros 50 anos do Brasil como colônia de Portugal (1500-1549), segundo Monlevade (1997, p. 19), os reis portugueses, ao contrário dos espanhóis, que fundaram escolas, colégios e universidades em suas colônias americanas do Caribe, Atlântico e do Pacífico, resolveram fazer no País uma "educação sem escola e sem despesas". A escola formal foi negada aos adultos e crianças índias, assim como aos brancos missionários e, portanto, não houve gasto com professores/as.

A sociedade colonial, inicialmente organizada em capitanias hereditárias, provocou as primeiras mudanças na estrutura social e política do País, mas o sistema fracassou em função 
O Piso Salarial Nacional no Contexto do Financiamento da Educação no Brasil

da grande distância da Metrópole, da falta de recursos e outros, exigindo que o Estado português se fizesse presente na pessoa do Governador Geral, primeiro na Bahia e depois no Rio de Janeiro, cercado de militares e fiscais que garantiram a ordem colonial e o fluxo de impostos para dar sustentação ao luxo da Corte em Lisboa. Dessa forma, a principal forma de tributação no Brasil Colônia era o Quinto, que correspondia a $20 \%$ das extrações das minas de ouro, prata ou ouro metal, a que a realeza tinha direito. A nova organização social estabelecida nesse período, com fazendas de casa-grande e senzala, cidades de sobrados e mocambos, por sua vez, clamou por escolas e professores que ensinassem a fé e os costumes, ou, como afirma Monlevade (1997), que educassem uns para mandar e outros para obedecer.

É nesse contexto que a Corte portuguesa delega concessão real aos jesuítas para assumirem a educação básica no Brasil, inaugurando, pois, 200 anos de escola pública sem despesas para o Estado (1549 a 1758).

Com a expulsão dos jesuítas do Brasil, a educação escolar entre 1758 e 1772, na Colônia, caracterizou-se como zero de educação pública, uma vez que o que se instituiu nesse período foi o esquema de aulas régias, obra prima política do Marquês de Pombal, que assim funcionava: a pessoa que soubesse um pouco mais que outras, e quisesse lecionar, procurava um vereador da Câmara Municipal local que, por sua vez, solicitaria ao rei uma permissão para o interessado assumir a aula pretendida em nível primário ou secundário, devia matricular os alunos e recebia da Câmara 'um vencimento mensal', fruto de um imposto criado para este fim, o "subsídio literário", taxa cobrada das destilarias de cachaça e açougues, que eram as duas atividades econômicas do mercado local na época.

A partir de 1800 várias mudanças sociais, políticas e econômicas ocorreram no Brasil com a vinda da família Real para a Colônia: a) crescimento das cidades de Salvador e Rio de Janeiro, como polos comerciais e administrativos da metrópole provisória; b) Independência do Brasil em 1822 e D. Pedro I como Imperador, em 1824, outorga a primeira Constituição brasileira, seguida da Primeira Lei de Ensino (1827), que garantia ensino público e gratuito em todas "as villas e logares do pays" (MONLEVADE, 1997, p. 27). Nesse contexto, foram implantadas as Províncias, reduzindo o poder local das Câmaras Municipais e criando as bases da federação e da unidade nacional. As transformações ocorridas favoreceram o impasse instaurado no sistema educacional brasileiro nesse período: o crescimento da demanda de alunos para cursos primários e secundários e a escassez de recursos humanos (os jesuítas haviam sido expulsos) e financeiros para abrir e manter as escolas, uma vez que a Corte portuguesa retornou para Lisboa, repatriando ouro e professores. A crise na oferta de escolas públicas favoreceu o surgimento dos primeiros empresários do ensino, que ofereciam escolas pagas no Rio de Janeiro e outras cidades maiores. Como se vê, as aulas régias, além de insuficientes para atender a demanda, continuavam descentralizadas e desqualificadas. Quanto aos docentes e os seus salários, a indicação era feita pelas Câmaras Municipais e, a nomeação, pelo Rei ou Imperador, inaugurando a submissão política daqueles às autoridades e interesses do governo.

Em 1834, por força do Ato Adicional à Constituição de 1824 e das Constituições Estaduais, a responsabilidade em oferecer instrução elementar em escolas primárias e secundárias públicas passa do governo central do Império para as Províncias, favorecendo a descentralização da educação pública, aproximando o usuário da autoridade responsável 
O Piso Salarial Nacional no Contexto do Financiamento da Educação no Brasil

local. Todavia, as províncias foram agravadas com um encargo a que não puderam responder devido à falta de recursos financeiros, humanos e materiais, deixando os seus representantes eleitos às voltas com dois grandes problemas: garantir escolas primárias e secundárias para os filhos dos eleitores e 'melhores salários' para os professores. Segundo Nagle (1974), a principal característica do ato adicional foi delimitar competências das assembleias legislativas provinciais e do governo central no campo das instruções, estabelecendo-se, assim, a tendência de o governo central responsabilizar-se pelo ensino superior e, as esferas locais, pelas séries iniciais, denotando o fato de, conforme Rossinholi (2010), ter sido muito mais uma característica política e social que estabeleceu o descomprometimento com a formação de base em detrimento ao ensino superior.

Quanto ao financiamento das ações educacionais, a expansão das cidades também favoreceu a demanda pelo comércio de mercadorias, o que viabilizou a cobrança de tributo correspondente ao atual Imposto sobre Circulação de Mercadorias e Serviços (ICMS), o que corroborou para a multiplicação de escolas primárias e secundárias, a cargo das províncias do Império e, a partir de 1889, dos estados da República. Todavia, sendo a maioria da população consumidora residente na zona rural, os bens de consumo eram produzidos no próprio local, não circulando no mercado regional e nacional, escapando do fisco. Assim, a arrecadação de impostos era insuficiente para construir e custear mais escolas públicas, gerando grandes disparidades na oferta educacional entre os estados brasileiros desde aquela época, bem como desigualdade salarial entre os/as docentes.

$\mathrm{Na}$ década de 1930, o processo de urbanização e industrialização intensificou-se no Brasil, havendo em correspondência uma explosão educacional devido ao ajuste seletivo ao capitalismo industrial. Novas demandas surgiram, como saneamento, rodovias, fontes de energia mantidas com recursos públicos, bem como o surgimento de escolas municipais financiadas por seus tributos.

Em 1934 foi promulgada a primeira Constituição Federal (CF) brasileira a vincular uma percentagem de recursos para a educação, provenientes da receita de impostos: $10 \%$ - União; $20 \%$ - estados e Distrito Federal; e, 10\% - municípios. Além da vinculação de recursos, a $\mathrm{CF} / 34$ exigiu que os profissionais do magistério adentrassem ao serviço público através de concurso de provas e títulos e, embora não faça menção ao salário docente, deixou subtendido que estes profissionais não poderiam receber menos do que um "salário mínimo" (conquista trabalhista criada nessa Constituição), pois proibia qualquer tipo de distinção salarial baseada em critérios de sexo, idade, nacionalidade e estado civil.

A CF/1937, outorgada no governo de Getúlio Vargas, implantou a ditadura do Estado Novo e representou um retrocesso na educação em relação à sua predecessora. Suprimiu a vinculação da receita de impostos destinados à pasta e o ensino, embora continuasse gratuito e obrigatório, dos menos necessitados cobrava-se uma contribuição mensal para a caixa escolar como forma de solidariedade. Quanto ao piso salarial docente, este também não é tratado na Constituição de 1934, ficando a remuneração desses profissionais vinculada ao salário mínimo.

Por sua vez, a CF de 1946, no art. 169, retomou os impostos federais e, quanto aos impostos municipais para a educação, vinculou uma percentagem do Fundo de Participação dos Municípios e outra das receitas tributárias próprias, ficando assim determinada: União 10\%; estados e Distrito Federal - 20\%; Municípios - 20\%. Com relação ao professor, exigia 
O Piso Salarial Nacional no Contexto do Financiamento da Educação no Brasil

apenas a entrada deste no serviço público através de concurso de provas e títulos; nem uma referência à questão salarial, presumindo-se que percebiam apenas o salário mínimo.

$\mathrm{Na}$ Lei de Diretrizes e Bases da Educação de 1961, LDB 4.024/61 (BRASIL, 1961), os percentuais a serem gastos pela União com a educação foram alterados de $10 \%$ para $12 \%$, permanecendo os mesmos $20 \%$ para estados, Distrito Federal e municípios. No artigo $\mathrm{n}^{\circ} 92$, parágrafo $1^{\circ}$, foram constituídos os fundos nacionais do ensino primário, ensino médio e do ensino superior com nove décimos dos recursos destinados à educação (ROSSINHOLI, 2010), o que, segundo Oliveira (1999), caracterizou menos recursos para o ensino primário, uma vez que o número de alunos não era o mesmo para todos os níveis e o ensino primário era gratuito e obrigatório - fato que acarretou em salas de aulas superlotadas e salários miseráveis para o professor.

O Governo Militar, também nessa época, criou a contribuição adicional do salárioeducação, muito embora essa vinculação tenha sido relaxada após 1964, sendo suprimida pela CF de 1967, promulgada durante a Ditadura Militar. Para Germano (1994), esse período revelou um profundo descomprometimento com o financiamento da educação pública e gratuita, negando na prática a valorização da educação escolar e incentivando a privatização do ensino, transformando-o num negócio rendoso e subsidiado pelo Estado. A Emenda Constitucional de 1969 retrata bem isso quando vincula recursos somente na esfera do município (20\%), favorecendo assim a iniciativa privada. De acordo com Monlevade (1997), sem dúvida foram o ICM dos estados desenvolvidos e o FPM dos municípios subdesenvolvidos que financiaram a educação pública na década de 1960. Quanto aos professores públicos da educação básica, o flagelo e a desvalorização tomou conta da categoria com o aumento de aulas e/ou multijornada de trabalho, formação aligeirada e arrocho salarial.

O período correspondente aos anos de 1970 e aos anos antecedentes da Carta Magna de 1988 foi caracterizado por muitas contradições no cenário educacional brasileiro, e entre estas: a lenta ampliação da educação infantil e do ensino médio público; o sufocamento dos movimentos de alfabetização; o fracasso da proposta de profissionalização do ensino médio; a explosão de nichos de oferta do ensino particular; a descaracterização das Escolas Normais e desqualificação das Licenciaturas, entre outros. Estas duas últimas contradições apontadas denotam a não valorização da profissão docente, pois atacam diretamente a sua formação/qualificação, bem como o salário da categoria.

A LDB 5692/71 foi o marco desse período, pois, além de fixar as diretrizes e bases para o ensino de $1^{\circ}$ e $2^{\circ}$ graus, tornou a escolarização obrigatória em 08 anos e estabeleceu a aplicação de $20 \%$ do FPM no ensino. Acentua-se nesse período a desproporção dos encargos: alguns municípios pobres com muitos alunos nas suas redes e outros ricos com poucos alunos matriculados no $1^{\circ} \mathrm{grau}$. Para Oliveira (1999), a LDB 5692/71 implicou avanços no sentido da descentralização, pois atribuiu responsabilidades aos Conselhos Federal e Estadual de Educação, aos estabelecimentos de ensino, além da criação dos Conselhos Municipais de Educação onde fosse possível; mas o controle e as decisões foram mantidos na União. Quanto aos profissionais do ensino, exigiu-se a formação mínima, licenciatura plena, e, quanto ao salário, instituiu em seu artigo n. 39 que "[...] os sistemas de ensino devem fixar a remuneração dos professores e especialistas de ensino de $1^{\circ}$ e $2^{\circ}$ graus, tendo em 
O Piso Salarial Nacional no Contexto do Financiamento da Educação no Brasil

vista a maior qualificação em cursos e estágios de formação, aperfeiçoamento ou especialização, sem distinção de graus escolares em que atuem" (BRASIL, 1971).

No final da década de 1970 e início da de 1980, com o agravamento da crise econômica e situação financeira no País por causa do endividamento interno e externo do setor público, houve uma grande pressão para mudanças no setor tributário de forma a aumentar as receitas dos estados e municípios e contribuir para o estabelecimento do federalismo fiscal no Brasil. De acordo com Melchior (1987), nesse período os gastos do MEC estavam concentrados no ensino superior (69,09\% em 1978), havendo, portanto, a necessidade de descentralização de recursos para que estados e municípios pudessem investir nos outros níveis de ensino. Essas mudanças vieram com a Emenda Passos Porto, que operou uma minirreforma tributária, aumentando a participação dos estados, Distrito Federal e municípios nas receitas da União, elevando o Fundo de Participação dos Municípios (FPM) e o Fundo de Participação dos Estados (FPE), fundos compostos dos principais impostos arrecadados e transferidos da União: o Imposto sobre Produtos Industrializados (IPI) e o Imposto de Renda e proventos (IR). Aprovada na sequência, a Emenda João Calmon também trouxe mudanças, uma vez que fixou percentuais mínimos das receitas próprias e transferências constitucionais para o investimento em educação: a União deveria investir o mínimo de $13 \%$ e, os estados, Distrito Federal e municípios, o mínimo de $25 \%$.

Essas medidas foram tomadas para aumentar a participação dos estados e municípios: a carga tributária aumentou com a elevação do IR e, juntamente a isso, houve elevação do percentual que compunha o FPM e FPE, buscando fortalecer os estados e municípios e rediscutir o federalismo no Brasil. Todas essas mudanças, segundo Melchior (1987), levaram à configuração assumida pela Constituição Federal (CF) de 1988 e, principalmente, deveriam levar à melhoria da educação.

A CF/88, como afirma Rossinholi (2010), caracterizou-se pela descentralização financeira, representando um aumento da participação dos estados e principalmente de municípios na arrecadação tributária e na receita disponível. Também manteve, conforme Amaral (2012), a contribuição paga pelas empresas, chamada salário-educação, que deveria dirigir-se, obrigatoriamente, ao financiamento da educação básica.

Ademais, estipulando no seu artigo 205 "a educação como direito de todos e dever do estado e da família”, a Carta magna de 1988 (BRASIL, 1988) permitiu que a educação devesse ser financiada tanto com recursos públicos arrecadados da população brasileira quanto com recursos oriundos das famílias por meio do pagamento de mensalidades, no caso das escolas privadas, pois no seu artigo 206 determina que as escolas públicas devam ser gratuitas. E, no artigo 212, estabeleceu-se a vinculação do mínimo de recursos financeiros arrecadados de impostos pagos pela população, que devem ser aplicados nas escolas públicas do País: a União aplicará nunca menos que $18 \%$ e estados, Distrito Federal e municípios o mínimo de $25 \%$, na manutenção e desenvolvimento do ensino (MDE). E, dentre as despesas consideradas MDE, está "remuneração e aperfeiçoamento do pessoal docente e demais profissionais da educação", conforme preconiza a LDBEN 9.394/1996, artigo 70 (BRASIL, 1996b).

Os recursos arrecadados pela União são transferidos aos estados e municípios e parte dos impostos arrecadados pelos estados é transferida aos municípios. No caso dos municípios, estes devem aplicar o mínimo de $25 \%$ dos impostos por eles arrecadados, 
O Piso Salarial Nacional no Contexto do Financiamento da Educação no Brasil

adicionando-se os repassados pela União e pelos estados. Assim, para compreender o financiamento da educação brasileira, é necessário, primeiramente, o entendimento de que os recursos públicos são provenientes da arrecadação de impostos oriundos da sociedade e da contribuição do salário-educação recolhido das empresas e que são colocados à disposição dos governos federais, estaduais, distritais e municipais para implementação de políticas públicas.

Ainda sobre a CF/88, destaca-se também o fato de esta ter instituído a educação como um direito constitucional dos indivíduos, bem como um direito "público subjetivo" (art. 208). Sobre isso, Oliveira (2002, p. 15) enfatiza que "o direito à educação é hoje reconhecido como um dos direitos fundamentais do homem e é consagrado na legislação de praticamente todos os países", o que caracteriza a educação como um direito fundamental para o pleno exercício da cidadania. E, para concretização desse direito, os legisladores, durante a sua construção, destacaram como essencial o regime de colaboração entre entes federativos para cumprimento desse dever: "A União, os estados, o Distrito Federal e os municípios organizarão em regime de colaboração seus sistemas de ensino" (BRASIL, 1988, art. 211). O artigo 211, parágrafo $1^{\circ}$, ainda destaca que a União exercerá, em matéria educacional, a função redistributiva e supletiva, de forma a garantir equalização das oportunidades educacionais e padrão mínimo de qualidade de ensino mediante assistência técnica e financeira aos estados, ao Distrito Federal e aos municípios (grifo nosso). Esse aspecto fora destacado, haja vista o artigo $4^{\circ}$ da Lei $n^{\circ} 11.738 / 2008$, Lei do Piso, determinar que a União deve complementar financeiramente os recursos dos entes federativos que justificarem e comprovarem sua necessidade e incapacidade orçamentária para pagamento do piso salarial docente.

Quanto à categoria magistério e sua valorização, após 161 anos a contar da primeira Lei do Ensino, em 1827, que previa o pagamento de salários como forma de valorizar os professores, a CF/88 trouxe em seu artigo 206 , entre os princípios basilares para a ministração do ensino, o inciso $V$ com o seguinte texto: "[...] valorização dos profissionais do ensino, garantido, na forma da lei, plano de carreira para o magistério público, com piso salarial profissional e ingresso exclusivamente por concurso público de provas e títulos, assegurado regime jurídico único para todas as instituições mantidas pela União" (BRASIL, 1988, art. 206). Ainda não foi dessa vez que o piso salarial para o magistério foi orientado para ser instituído 'nacionalmente'.

Diante do exposto, depreende-se que a questão do direito à educação se fez presente nas diversas Constituições do País e a gratuidade, que aparece na CF de 1824, colocou o Brasil entre os primeiros países do mundo onde a educação gratuita aparece na legislação, mas sem, no entanto, ser efetivamente transformada em política pública e garantida de fato à população. Isso porque, para garantir a oferta do ensino público gratuito e de qualidade para todo e qualquer cidadão brasileiro, faz-se necessário contar com a disponibilidade de recursos públicos suficientes para dar sustentação às diversas políticas públicas educacionais. Além disso, conclui-se também da análise empreendida que a valorização docente, sustentada nos pilares formação e remuneração condigna através da instituição de um piso salarial nacional, não se fez presente nas constituições brasileiras. A CF/88 recomenda garantir o piso salarial como forma de valorizar os profissionais, mas o fato de não instituir o termo "nacionalmente" 
O Piso Salarial Nacional no Contexto do Financiamento da Educação no Brasil

abriu procedência para que estados e municípios criassem os próprios pisos salariais, o que acentuou as desigualdades salariais já existentes entre os entes federados.

De acordo com Monlevade (1997), nos anos posteriores à promulgação da Carta Magna de 1988 a União investia os seus $18 \%$ cada vez mais no ensino superior e cada vez menos no ensino fundamental, além de cortar $20 \%$ dos $18 \%$ para um Fundo Social de Emergência (atual DRU), quando da inauguração do Plano Real, através da desvinculação de receitas da União, mecanismo que permitia ao governo federal usar livremente $20 \%$ de todos os tributos federais arrecadados de contribuições sociais, comprometendo os FPM e FPE. Complementando a crise que se agravou, inexistia no País um Plano Nacional de Educação e uma liderança da União para ordenar os gastos da educação, o que levou os estados e municípios a pensar políticas próprias para enfrentar a sobrecarga, as despesas e os desafios da demanda.

É no contexto apresentado que se realizam, no Fórum Permanente de Valorização do Magistério, estudos com o objetivo de resolver o problema da desvalorização salarial do professor, propondo a viabilização de "[...] um Piso Salarial Profissional Nacional, através da articulação das receitas da União, Estados e Municípios através de Fundos" (MONLEVADE, 1997, p. 65). Assim, em 1994, dois importantes instrumentos foram articulados: o Acordo Nacional e o Pacto Nacional pela Valorização do Magistério e pela Qualidade do Ensino. Contudo, após a posse do presidente Fernando Henrique Cardoso, em janeiro de 1995, o ministro da educação, Paulo Renato Souza, não considerou o Piso salarial nacional como um insumo importante para a solução dos problemas detectados no Fórum, mas propôs a criação de Fundos Estaduais, que objetivava o equilíbrio das destinações de verbas vinculadas às redes estaduais e municipais de cada estado, pelo critério da disponibilidade de recursos proporcionais ao número de matrículas de cada rede. No ano seguinte (1996) foi criada a Emenda Constitucional (EC) n. 14/96, que regulamentou o Fundo de Manutenção e Desenvolvimento do Ensino Fundamental e Valorização do Magistério (Fundef) e que trouxe modificações ao texto do artigo 60 da CF/88 no que se refere à universalização do ensino e à remuneração do professor. É exatamente sobre os fundos de financiamento da educação (Fundef e Fundeb) e seus contributos para a instituição de um piso salarial nacional para os profissionais da educação que trataremos a seguir.

\section{A Política de Fundos (Fundef/Fundeb) de financiamento da educação brasileira}

A ideia da constituição de um fundo de recursos financeiros para o financiamento da educação no Brasil remonta à década de 1960, quando o educador Anísio Teixeira, em seu livro Educação um direito, publicado em 1968, fez uma análise sobre a CF de 1946 no que se refere aos percentuais mínimos estabelecidos na época (10\% União e $20 \%$ estados e municípios) para serem aplicados no financiamento da educação brasileira, no qual afirmou que esses recursos deveriam ser utilizados de forma solidária entre os entes federados por meio da criação de um fundo que os contivessem, podendo ser utilizados na diminuição das desigualdades econômicas e culturais que levariam à formação desigual dos alunos.

O Fundo de Manutenção e Desenvolvimento do Ensino Fundamental e de Valorização do Magistério (Fundef), criado pela EC 14/96, era composto de parte dos recursos vinculados pela Constituição Federal de 1988 (15\% do FPE, do FPM, do ICMS, do IPI-Exp e da 
O Piso Salarial Nacional no Contexto do Financiamento da Educação no Brasil

Desoneração de Exportações - Lei Kandir) e que deveriam ser aplicados exclusivamente no ensino fundamental. Esse fundo era constituído em cada estado e o seu objetivo era redistribuir os recursos, retirando recursos de alguns municípios e remetendo a outros, como meio de uniformizar o valor aplicado por aluno dentro daquele estado, no ensino fundamental. O valor-aluno, por sua vez, era divulgado pelo governo federal, que tinha o dever de suplementar os recursos caso algum estado não atingisse esse valor mínimo anual por aluno estabelecido. Com relação à questão do valor-aluno/anual, estudiosos do assunto, como Davies (1998) e Monlevade e Ferreira (1997), criticaram os valores divulgados nos anos posteriores à promulgação da Lei 9.424/1996, que instituiu o Fundef. O artigo $6^{\circ}$ estipulou que, exceto no primeiro ano de vigência do Fundo, em que o valor mínimo anual por aluno deveria ser $\mathrm{R} \$ 300,00$, nos anos posteriores o valor anual seria fixado por ato do Presidente da República e não poderia ser inferior à previsão da receita total do fundo e à matrícula total dos alunos do ensino fundamental do ano anterior, acrescida da estimativa de matrícula. Todavia, Monlevade e Ferreira (1997), numa análise feita no ano de 1998, afirmam que, embora o Ministério da Fazenda tivesse projetado valores da arrecadação total do fundo e da matrícula de alunos que resultasse num valor mínimo correspondente a $R \$ 423,07$, o governo federal divulgara o valor mínimo como sendo $R \$ 315,00$, descumprindo o estabelecido na lei.

Com relação à subvinculação de recursos, o Fundef estipulou o mínimo de $60 \%$ de recursos do fundo para serem gastos com o pagamento dos profissionais do magistério, e os $40 \%$ restantes com as atividades relacionadas ao MDE. Além disso, o Fundef tinha como objetivo o estabelecimento de recursos mínimos para o ensino fundamental, garantindo aos estados e Distrito Federal, que não apresentassem condições de cumprir o valor mínimo por aluno necessário para o estabelecimento de um padrão de qualidade, com recursos próprios, a complementação de recursos da União (art. $5^{\circ}$ ). Entretanto, de acordo com Rossinholi (2010), o baixo valor complementado pela União ao Fundef não levou à redução das desigualdades regionais originadas pelas diferenças de arrecadação entre os estados, mas sim ao baixo comprometimento financeiro da União com a educação básica.

Para melhor retratar essa situação, vale destacar que a EC n. 14/96 também alterou o artigo 211 da CF/88, determinando a "[...] atuação prioritária dos estados, no ensino fundamental e médio, e dos municípios, na educação infantil e no ensino fundamental, devendo a União agir complementarmente na educação básica" (BRASIL, 1996a, art. 211). Essa alteração provocou um aligeiramento no processo de municipalização do Ensino Fundamental Regular (EFR), pois o critério para vinculação de recursos do Fundef era o número de alunos efetivamente matriculados no EFR. Entretanto, a municipalização induzida desencadeou algumas críticas, pois a maioria dos municípios brasileiros não possuíam condições adequadas, seja na parte física, administrativa ou na preparação docente para assumir um aumento tão repentino na quantidade de alunos. As críticas mais evidentes foram as relacionadas à preocupação excessiva da municipalização com o aumento de recursos financeiros e não com a melhor forma de oferecimento do ensino fundamental.

Para Pinto (2002), o Fundef pouco acrescentou à situação inicial do financiamento da educação. Com a desresponsabilização da União, pouco se podia fazer para a redução das desigualdades regionais. Conforme Rossinholi (2010), em 2005, a participação de cada ente federado nas contribuições existentes ocorria da seguinte maneira: $94,2 \%$ para a União, $4,64 \%$ para os estados e $1,14 \%$ para os municípios, sendo que as contribuições 
O Piso Salarial Nacional no Contexto do Financiamento da Educação no Brasil

representavam $35,91 \%$ da receita tributária brasileira. Em outras palavras, a União teria capacidade financeira para melhor complementar os entes federados, de forma a promover, ao invés da redistribuição de recursos entre os estados e seus municípios, uma redistribuição nacional, que seria mais justa; mas, de acordo com a análise realizada por Castro e Duarte (2007) sobre a relação de gastos em educação, no período de 1995-2005, houve na verdade uma redução de $32,93 \%$ dos recursos aplicados pela União no ensino fundamental, enquanto os gastos municipais aumentaram em $127,43 \%$.

Assim, embora a quase universalização do ensino fundamental fosse considerada um aspecto relevante do fundo, os aspectos negativos se sobressaíram mais, como: "[...] o descaso originado em outros níveis de ensino, a desresponsabilização da União, baixos recursos existentes e incapacidade de redução das desigualdades regionais, a municipalização induzida e acelerada, além de problemas na gestão e controle do fundo [...]" (ROSSINHOLI, 2010, p. 80). Ademais, as desigualdades regionais contribuíram para acentuar ainda mais gritantes diferenças salariais entre os professores brasileiros, além da intensificação e precarização do trabalho docente devido à municipalização aligeirada. Foram tais aspectos que contribuíram e influenciaram na elaboração do seu substitutivo: o Fundo de Manutenção e Desenvolvimento da Educação Básica e de Valorização dos Profissionais da Educação (Fundeb).

A EC 53/2006 que criou o Fundeb incorporou algumas críticas com relação ao antigo Fundef e outras não. Incluiu o parágrafo $5^{\circ}$ ao artigo 211 da CF/88, reafirmando que a prioridade é o ensino regular, agora de toda a educação básica. Altera o $\S 5^{\circ}$ do artigo 212 , substituindo a referência ao ensino fundamental pela educação básica no recebimento do salário-educação; também incluiu, nesse mesmo artigo, o parágrafo $6^{\circ}$, que estabelece cotas estaduais e municipais proporcionais ao número de alunos na distribuição do salárioeducação. Também altera no artigo 60, das Disposições Transitórias, o período de duração do novo fundo de financiamento da educação para 14 anos, bem como a sua composição. Os impostos que já faziam parte do Fundef têm seu percentual alterado de $15 \%$ para $20 \%$, gradativamente, no prazo de três anos $(16,66 \%$, no primeiro ano; $18,33 \%$, no segundo; e $20 \%$ a partir do terceiro ano). Quanto à complementação da União, que a partir do quarto ano de vigência do Fundeb passou a ser o equivalente a $10 \%$ do valor total dos recursos do fundo, Rossinholi (2010) considera como ganho importante para a educação brasileira, pois se diferiu do texto proposto pelo Executivo inicialmente, em que os valores eram bem menores.

Para a remuneração dos profissionais do magistério, o Fundeb mantém a vinculação do percentual de $60 \%$ dos recursos do fundo para esse fim, alterando apenas a redação, visto que, na EC 14/96, fazia referência ao pagamento apenas dos professores do ensino fundamental em efetiva docência. Além disso, fora estipulado prazo para fixar, em lei específica, o "piso salarial nacional", além de reiterar a obrigação de planos de carreira e remuneração, com capacitação profissional através da formação continuada com vistas à melhoria da qualidade do ensino. Sobre essa suposta valorização, Davies (2008) afirma que é um equívoco achar que apenas aplicando o mínimo de $60 \%$ dos recursos do Fundeb para a remuneração dos professores da educação básica resultaria em sua valorização, pois o referido fundo não representa a totalidade dos recursos vinculados à educação, ficando de fora o salário-educação, os $25 \%$ dos impostos municipais próprios (IPTU, ISS, ITBI) e do IR dos servidores municipais, etc. 
O Piso Salarial Nacional no Contexto do Financiamento da Educação no Brasil

O panorama apresentado, sobre os fundos de financiamento da educação, permitiu concluir que estes trouxeram poucos recursos novos à educação brasileira, uma vez que apenas promoveram a redistribuição, entre governo estadual e prefeituras, de recursos provenientes de impostos antes já vinculados à manutenção e desenvolvimento da educação (MDE). Segundo Davies (2008), os únicos recursos novos foram os da complementação federal, considerados pelo autor como insignificantes no Fundef ( $1 \%$ da receita nacional em 2006) e muito pouco no Fundeb (menos 5\% da receita nacional em 2007 e $10 \%$ a partir de 2010). Entretanto, vale ressaltar que o valor estimado para o Fundeb, em 2010, era de cinco bilhões de reais, considerado inferior ao que a União retirava da educação através da Desvinculação de Receitas da União (DRU), mecanismo que permite ao governo federal usar livremente $20 \%$ de todos os tributos federais vinculados por lei a fundos ou despesas. Ou seja, na prática, a DRU permite que o governo aplique os recursos destinados a áreas como educação, saúde e previdência social em qualquer despesa considerada prioritária e na formação de superávit primário, possibilitando também o manejo de recursos para o pagamento de juros da dívida pública. A situação exposta deixa claro que a complementação da União aos estados e municípios, no período citado, ficou neutralizada pelo valor que o governo federal retirava (e ainda retira) da educação com a DRU. E, finalmente, entre as fragilidades apresentadas, com relação à política de Fundos, estão as poucas chances de um salto significativo na melhoria salarial dos professores, uma vez que alguns municípios perderam com os fundos.

\section{O Piso Salarial Nacional para os professores da Educação Básica e o seu financiamento}

O Piso Salarial Nacional Profissional (PSPN) tem como importante função equalizar a educação nacional, tão marcada por iniquidades regionais, além de constituir-se num insumo necessário para a valorização dos profissionais da educação, encarada como condição imprescindível para a garantia da eficácia na educação. Porém, foram necessárias duas décadas de estudos e debates desde a Constituição de 1988 (quando o termo "piso salarial" apareceu pela primeira vez numa legislação brasileira) até chegar à Lei 11.738/2008 e se instituir de fato o piso salarial profissional nacional para os profissionais do magistério público da educação básica.

Têm direito ao piso todos os profissionais do magistério público da educação básica que trabalham dentro da escola: professores e todos os que dão suporte ao processo ensino e aprendizagem (diretores, coordenadores e orientadores pedagógicos, supervisores, etc.). A Lei do Piso também explicita que a sua implantação deveria acontecer gradualmente, entre 2009 e 2010, e ser reajustado anualmente, de forma automática, com base no crescimento do valor anual mínimo gasto por aluno do ensino fundamental, de acordo com as regras do Fundo de Manutenção e Desenvolvimento da Educação Básica e Valorização dos Profissionais do Magistério (Fundeb). Outra exigência é que estados e municípios teriam que elaborar ou adequar seus planos de carreira e remuneração do Magistério às exigências da lei do piso até dezembro de 2009. Finalmente, como garantia para o cumprimento do piso salarial, a lei dispõe sobre a participação da União no seu custeio e na sua implementação progressiva. 
O Piso Salarial Nacional no Contexto do Financiamento da Educação no Brasil

Assim, após ser sancionada em julho de 2008, a Lei do Piso gerou expectativas de que pudesse ser capaz de cumprir com os objetivos pelos quais é defendida pela categoria dos profissionais do magistério. Isto é, tornar-se não apenas um parâmetro salarial nacional, mas, sobretudo, garantir uma valorização que de fato corrobore para a melhoria do ensino através do combate à multijornada de trabalho e ao subemprego. Entretanto, o que se apresenta, atualmente, é um cenário não muito otimista.

Atualmente, embora tenha passado uma década desde a sanção da Lei $\mathrm{n}{ }^{\circ}$ 11.738/2008, que regulamenta a alínea "e" do inciso III do caput do art. 60 do Ato das Disposições Constitucionais Transitórias (ADCT) para instituir o piso salarial profissional nacional para os profissionais do magistério público da educação básica (PSPN), os embates em torno da mesma questão continuam em alta, principalmente no tocante à inviabilidade de pagamento alegada por alguns estados e municípios, de acordo com cada reajuste anual dado; isto é, gestores de vários estados e municípios brasileiros, sobretudo do Nordeste, alegam falta de recursos para seu cumprimento.

Desse modo, para a compreensão de como se instaurou tal problemática necessário se faz entender em que contexto essa política pública de valorização docente foi gestada.

Segundo Vieira (2010, p. 72-73), a pergunta determinante que se buscou responder e reforçou a criação da Emenda Constitucional n. 53/2006, que alterou os artigos 206 da CF/88 e o artigo 60 das Disposições Transitórias da mesma Constituição, que remetem à Lei do Piso, foi: "como, atualmente, estados e municípios fixam vencimentos iniciais de carreiras?". Conforme a autora, na maioria dos casos, os recursos financeiros eram repartidos desigualmente entre os servidores municipais, com professores recebendo até 100 vezes menos que outros servidores com o mesmo tempo de escolaridade. A autora ainda pontua que, no período que antecedeu à aprovação da Lei do PSPN, a Confederação Nacional dos Trabalhadores em Educação (CNTE) elencou alguns aspectos a serem considerados na fixação do Piso salarial, evidenciando, principalmente, a relevância das fontes de financiamento para a composição do Piso, o que exige da União não apenas a complementação que esta fará aos estados que não alcançarem os valores mínimos do custoaluno anual, mas que, sobretudo, faça aportes financeiros específicos para garanti-lo.

Quanto ao processo de instituição do PSPN, Vieira (2013) afirma que este não transcorreu pacificamente no Congresso Nacional nem entre gestores, o que pode ser confirmado pelas inúmeras mudanças no texto do Projeto de Lei (PL) n ${ }^{\circ}$ 619/2007 encaminhado pelo Executivo antes da aprovação da Lei $n^{\circ} 11.738 / 2008$; bem como, após a sua sanção, pela Ação Direta de Inconstitucionalidade (ADIN) impetrada por seis estados brasileiros. Embora as dificuldades citadas tenham tumultuado o processo, o PL que institui o PSPN foi unanimemente aprovado pelo parlamento brasileiro; unanimidade que, segundo a autora, funcionou apenas no plano discursivo, pois no plano real não se materializou devido aos percalços relacionados à política de aporte de recursos: eram poucas as "[...] alternativas de aumento de arrecadação fora de uma negociação da dívida interna e de uma reforma tributária que taxe o capital, o fluxo financeiro e as fortunas para que o Estado amplie os investimentos em políticas públicas" (VIEIRA, 2013, p. 201).

Vieira (2013) também afirma que, na conjuntura, houve a preocupação com a necessidade de adotar estratégias para prever mecanismos de financiamento para colocar o Piso na agenda nacional, ou seja, durante o processo de discussão da implantação da Lei, os 
O Piso Salarial Nacional no Contexto do Financiamento da Educação no Brasil

principais interessados já sabiam dos impasses que acabaram se apresentando, mesmo assim prosseguiram sem a alocação de recursos necessários para dar sustentação a essa política pública, que tem grande potencial de valorização profissional e de incidência sobre a qualidade da educação.

Também é importante destacar que a instituição do PSPN só foi possível no esteio do Fundeb, fundo que, apesar de diferenciar-se do antigo Fundef, trouxe poucos recursos tanto para o financiamento da educação quanto para dar sustentação ao cumprimento do piso salarial docente. Vale lembrar que o Fundeb, principal fonte de financiamento da educação, tem o seu mecanismo de subvinculação de recursos assim determinado: 60\% no mínimo para pagamento dos/as professores/as e $40 \%$ para outras despesas com ensino, como construção e reformas de escolas, transporte escolar, material didático, entre outros. Isto é, não se destina exclusivamente para pagamento do magistério. Apesar disso, de acordo com as pesquisas realizadas pela CNM em 2011, os dados do SIOPE/2009 revelaram que os municípios destinaram $73,3 \%$ dos recursos do Fundo com o pagamento dos docentes e utilizaram $29,1 \%$ dos investimentos municipais (FPM) com a manutenção e desenvolvimento da educação, demonstrando que estão acima do percentual mínimo determinado pela CF/88, que é de $25 \%$.

Conforme evidenciado, o Estado brasileiro é o promotor da política pública, neste caso da Lei $11.738 / 2008$, mas em muitos momentos ficou notória a sua falta de comprometimento com a complexa situação na qual se encontra o salário docente. Ou seja, por diversas vezes se esquivou do problema atribuindo maiores responsabilidades aos municípios, que são detentores de menos recursos quando comparados ao montante cumulado pela União.

Desse modo, para que a Lei do Piso cumpra o objetivo maior a que se propõe, que é a valorização docente através, principalmente, do recebimento de um salário condigno (quando equiparado ao de outras profissões com formação equivalente), será necessário o esforço conjunto de todos, União, estados e municípios, para alcançá-lo, pois os desafios que estão postos à frente são grandes.

O primeiro e grande desafio que se coloca à União (Estado brasileiro) é a urgência de uma reforma tributária no País. Uma reforma pautada nos princípios da equidade, progressividade e capacidade contributiva a caminho da justiça social e fiscal, priorizando a justa redistribuição de renda. Não se trata aqui da criação de novos impostos que venham sobrecarregar ainda mais as classes menos favorecidas, mas que o Brasil passe a arrecadar impostos diretos, como o Imposto Territorial Rural (ITR), que incide sobre a propriedade de terra, e que provoca, todos os anos, perda de bilhões de reais que poderiam consubstanciar políticas públicas educacionais com qualidade, como o pagamento do PSPN, entre outros serviços públicos sociais.

Outro importante desafio diz respeito à ampliação dos recursos que financiam o setor educacional no País, inclusive com a provisão de outras fontes de recursos, uma vez que o Fundeb, como se apresenta atualmente (insuficiente para dar sustentação ao PSPN), não poderá mais ser encarado como a "redenção" da educação básica (DAVIES, 2008). Para isso, os governos deverão eleger a educação pública como prioridade, aplicando-se mais que os percentuais mínimos determinados pela CF/88, no seu art. 212 (18\% e $25 \%$ dos impostos, no caso da União, Distrito Federal, estados e municípios, respectivamente), bem como trabalhar com afinco e em conjunto para o cumprimento da Meta 20 do Plano Nacional de Educação (PNE 2014-2024), instituído pela Lei N. 13.005 de 25 de junho de 2014 (BRASIL, 2014), que 
O Piso Salarial Nacional no Contexto do Financiamento da Educação no Brasil

trata do financiamento da educação brasileira; bem como para o cumprimento da Meta 17, que trata da melhoria do piso salarial nacional para o magistério público da educação básica, através da equiparação do seu rendimento médio ao dos demais profissionais com formação equivalente, até o final do sexto ano de vigência do plano. Entre as estratégias, que irão assegurar o cumprimento dessa meta, está a estratégia 17.4, que propõe a ampliação da assistência financeira específica da União aos entes federados para implementar política de valorização docente, em particular o PSPN.

Finalmente, é importante salientar que o investimento que um país faz na educação pública é medido calculando-se o volume de recursos financeiros aplicados neste setor social como percentual do PIB. Assim, tendo em vista os desafios apresentados, pode-se concluir que seu cumprimento exigirá um esforço coletivo dos governos (União, Distrito Federal, estados e municípios), de modo a incrementar os recursos educacionais para o equivalente a $10 \%$ do PIB, provando que de fato a educação é prioridade em suas agendas.

\section{Considerações Finais}

O cenário apresentado ao longo deste estudo desvelou o pouco investimento da União na educação no Brasil e, consequentemente, a desvalorização docente, que pode ser evidenciada pelo não interesse do poder público em estabelecer um piso nacional que possa promover a isonomia salarial entre os educadores brasileiros, num período de quase dois séculos, até se instituir a Lei n. 11.738/2008. Evidências estas que podem ainda ser ratificadas no levantamento realizado em 2014 pela Organização para a Cooperação e Desenvolvimento Econômico (OCDE), em que o Brasil ocupa o penúltimo lugar no ranking dos 35 países pesquisados que mais investem em educação, sendo o seu investimento por aluno e no salário docente, ao ano, três vezes menor que a média anual dos países da OCDE. $E$, obviamente, esse baixo investimento $(5,6 \%$ do PIB) tem interferido diretamente na qualidade do ensino oferecido, bem como na desvalorização do professor, pois ainda persistem salários aviltados, inexistência de planos de carreira, desigualdade salarial entre educadores e outros profissionais com o mesmo tempo de formação, entre outros.

Diante do exposto, é forçoso afirmar que o País não poderá mais postergar a ampliação de recursos financeiros necessários à melhoria da qualidade do ensino brasileiro e ao efetivo cumprimento de políticas educacionais voltadas para esse fim, como o PNE 2014-2024 e a Lei do Piso Salarial Nacional dos educadores brasileiros. Tais medidas preveem grande potencial de valorização docente, sendo necessário para isso o esforço conjunto de todos os entes federados para alcançar a elevação para $10 \%$ do percentual do Produto Interno Bruto a ser investido nesse setor social.

\section{Referências}

AMARAL, Nelson Cardoso. Para compreender o Financiamento da Educação básica no Brasil. Brasília: Liber Livro, 2012.

BRASIL. Constituição da República Federativa do Brasil. Diário Oficial da União, Brasília, 1988. Disponível em: <http://www.planalto.gov.br/ccivil_03/constituicao/constituicao compilado.htm>. Acesso em: 12 ago. 2014. 
O Piso Salarial Nacional no Contexto do Financiamento da Educação no Brasil

BRASIL. Emenda Constitucional $n^{\circ} 14$, de 12 de setembro de 1996. Modifica os artigos 34 , 208, 211 e 212 da Constituição Federal. Diário Oficial da União, Brasília, 1996a.

BRASIL. Lei de Diretrizes e Base da Educação Nacional - Lei n 9.394/96 - Estabelece as Diretrizes e Bases da Educação Nacional. Diário Oficial da União, Brasília, 1996b.

BRASIL. Lei no 9.424, de 24 de dezembro de 1996. Dispõe sobre o Fundo de Manutenção e Desenvolvimento do Ensino Fundamental e de Valorização do Magistério, na forma prevista no art. $60, \S 7^{\circ}$, do Ato das Disposições Constitucionais Transitórias, e dá outras providências. Diário Oficial da União, Brasília, 1996c.

BRASIL. Emenda Constitucional $n^{\circ} 53$, de 19 de dezembro de 2006. Dá nova redação aos arts. $7^{\circ}, 23,30,206,208,211$ e 212 da Constituição Federal e ao art. 60 do Ato das Disposições Constitucionais Transitórias. Diário Oficial da União, Brasília, 2006a.

BRASIL. Decreto № 6.003 de 28 de dezembro de 2006. Regulamenta a arrecadação, a fiscalização e a cobrança da contribuição social do salário-educação, a que se referem o art. 212, § 5o, da Constituição, e as Leis nos 9.424, de 24 de dezembro de 1996, e 9.766, de 18 de dezembro de 1998, e dá outras providências. Diário Oficial da União, Brasília, 2006b. Disponível em: <http://www.normaslegais.com.br/legislacao/decreto6003_2006.htm>. Acesso em: 23 jan. 2016.

BRASIL. Câmara Federal. Projeto de Lei n 619, de 28 de março de 2007. Regulamenta o art. 60, inciso III, alínea "e", do Ato das Disposições Constitucionais Transitórias, para instituir o piso salarial profissional nacional para os profissionais do magistério público da educação básica. Brasília, DF, 2007a. Disponível em: <http://www.camara.gov.br>. Acesso em: 05 fev. 2015.

BRASIL. Lei N. ${ }^{\circ} 11.494$, de 20 de junho de 2007. Regulamenta o Fundo de Manutenção e Desenvolvimento da Educação Básica e de Valorização dos Profissionais da Educação FUNDEB. Diário Oficial da União, Brasília, 2007b. Disponível em: <http://www.planalto. gov.br/ccivil_03/_ato2007-2010/2007/lei/l11494.htm>. Acesso em: 12 ago. 2014.

BRASIL. Lei Federal n. ${ }^{0} 11.738 / 2008$. Regulamenta a alínea "e" do inciso III do caput do art. 60 do Ato das Disposições Constitucionais Transitórias, para instituir o piso salarial profissional nacional para os profissionais do magistério público da educação básica. Diário Oficial da União, Brasília, 2008. Disponível em: <http://www.planalto.gov.br/ccivil _03/_ato2007-2010/2008/lei//11738.htm>. Acesso em: 12 ago. 2014.

BRASIL. Lei n. ${ }^{0} 13.005$, de 25 de junho de 2014. Aprova o Plano Nacional de Educação - PNE e dá outras providências. Diário Oficial da União, Brasília, DF, 26 jun. 2014. Edição extra.

CASTRO, Jorge Abrahão de; DUARTE, Bruno de Carvalho. Descentralização da educação pública no Brasil: evolução dos gastos e matrículas. In: REUNIÃO ANUAL DA ASSOCIAÇÃO NACIONAL DE PÓS-GRADUAÇÃO E PESQUISA EM EDUCAÇÃO - ANPED, 30., 2007, Caxambu. Anais... Caxambu: ANPED, 2007.

CONFEDERAÇÃO NACIONAL DE MUNICÍPIOS. Educação. O piso salarial nacional do magistério público em debate. Informativo CNM. Brasília, DF, 2011.

DAVIES, Nicholas. Política fiscal golpeia política educacional. Universidade e Sociedade (Brasília), São Paulo, v. VIII, n. 15, p. 60-64, 1998. 
O Piso Salarial Nacional no Contexto do Financiamento da Educação no Brasil

DAVIES, Nicholas. FUNDEB: a Redenção da Educação Básica? Campinas; São Paulo: Autores Associados, 2008.

GERMANO, José Willington. Estado militar e educação no Brasil. 2. ed. São Paulo: Cortez, 1994. MELCHIOR, José Carlos de Araújo. O financiamento da educação no Brasil. São Paulo: EPU, 1987.

MONLEVADE, João Antônio Cabral. Educação Pública no Brasil: Contos \& Descontos. Ceilândia-DF: Idea Editora, 1997.

MONLEVADE, João Antônio Cabral; FERREIRA, Eduardo. O Fundef e seus pecados capitais. Ceilândia-DF: Idea Editora, 1997.

NAGLE, Jorge. Educação e sociedade na primeira República. São Paulo: EPU, 1974.

OLIVEIRA, Carlos. A municipalização do ensino brasileiro. In: OLIVEIRA, Cleiton et al. (Org.). Municipalização do ensino no Brasil. Belo Horizonte: Autêntica, 1999. p. 11-36.

OLIVEIRA, Carlos. Gestão da educação: União, estado/Distrito Federal, município e escola. In: MACHADO, Lourdes Marcelino; FERREIRA, Naura Syria Carapeto (Org.). Política e gestão da educação: dois olhares. Rio de Janeiro: DP\&A, 2002.

PINTO, José Marcelino Rezende. Financiamento da Educação no Brasil: um balanço do Governo FHC (1995 a 2002). Educação e Sociedade, Campinas, v. 23, n. 80, p. 108-135, set. 2002.

ROSSINHOLI, Marisa. Política de financiamento da educação básica no Brasil: do FUNDEF ao FUNDEB. Brasília: Liber livro, 2010.

VIEIRA, Juçara Maria Dutra. Piso Salarial nacional dos educadores: dois séculos de atraso. 2. ed. rev. Brasília: CNTE, LGE, 2010.

VIEIRA, Juçara Maria Dutra. Piso salarial para os educadores brasileiros: quem toma partido? Campinas: Autores Associados, 2013.

Eliara Cristina Nogueira da Silva Teixeira é mestre em Educação na Universidade Estadual do Sudoeste da Bahia (UESB). Professora da Rede Pública Estadual de Ensino da Bahia (SEC/BA), município de Pindaí. Membro do Grupo de Estudos sobre Didática, Formação e Trabalho Docente (Difort/CNPq).

ORCID: http://orcid.org/0000-0001-5924-9124

E-mail: edyaraegui@hotmail.com

Claudio Pinto Nunes é doutor em Educação. Professor Titular da Universidade Estadual do Sudoeste da Bahia (UESB). Professor do Programa de Pós-Graduação em educação da UESB. Líder do Grupo de Estudos sobre Didática, Formação e Trabalho Docente (Difort/CNPq).

ORCID: http://orcid.org/0000-0003-1514-6961

E-mail: claudionunesba@hotmail.com 


\section{Editores do volume 9}

José Marcelino de Rezende Pinto - Universidade de São Paulo, São Paulo/SP, Brasil

Nalú Farenzena - Universidade Federal do Rio Grande do Sul, Porto Alegre/RS, Brasil

\section{Comitê Editorial}

José Marcelino de Rezende Pinto - Universidade de São Paulo, Brasil

Juca Gil - Universidade Federal do Rio Grande do Sul, Brasil

Theresa Adrião - Universidade Estadual de Campinas, Brasil Ângelo

Ricardo de Souza - Universidade Federal do Paraná, Brasil

Márcia Aparecida Jacomini - Universidade Federal de São Paulo, Brasil

\section{Conselho Editorial}

\section{Alejandro Morduchowicz}

Universidad Pedagógica, Provincia de Buenos Aires, Argentina

Fernanda Saforcada

Universidade de Buenos Aires, Argentina

Jacques Velloso

Universidade de Brasília, Brasil

João Monlevade

Senado Federal, Brasil

Jorge Abrahão de Castro

Instituto de Pesquisa Econômica Aplicada / IPEA, Brasil

Juca Gil

Universidade Federal do Rio Grande do Sul, Brasil

Lisete Regina Gomes Arelaro

Universidade de São Paulo, Brasil

Luis Carlos Sales

Universidade Federal do Piauí, Brasil

Luiz de Sousa Junior

Universidade Federal da Paraíba, Brasil

Luiz Fernandes Dourado

Universidade Federal de Goiás, Brasil

Magna França

Universidade Federal do Rio Grande do Norte, Brasil

\section{Maria Beatriz Luce}

Universidade Federal do Pampa, Brasil

Universidade Federal do Rio Grande do Sul, Brasil

Marcos Edgar Bassi

Universidade Federal de Santa Catarina, Brasil

\author{
Maria Dilnéia Espíndola Fernandes \\ Universidade Federal de Mato Grosso do Sul, Brasil \\ Nalú Farenzena \\ Universidade Federal do Rio Grande do Sul, Brasil \\ Nelson Cardoso do Amaral \\ Universidade Federal de Goiás, Brasil \\ Nicholas Davies \\ Universidade Federal Fluminense, Brasil \\ Rosana Evangelista Cruz \\ Universidade Federal do Piauí, Brasil \\ Rosana Gemaque \\ Universidade Federal do Pará, Brasil \\ Robert E. Verhine \\ Universidade Federal da Bahia, Brasil \\ Romualdo Portela de Oliveira \\ Universidade de São Paulo, Brasil \\ Theresa Adrião \\ Universidade Estadual de Campinas, Brasil \\ Tristan McCowan \\ University of London, Reino Unido \\ Vera Jacob \\ Universidade Federal do Pará, Brasil \\ Vera Peroni \\ Universidade Federal do Rio Grande do Sul, Brasil \\ Vitor Henrique Paro \\ Universidade de São Paulo, Brasil
}

\section{Equipe editorial}

Apoio ao Comitê Editorial: Patrícia Balthazar Garcia

Diagramação, Revisão de português e normalização: Edson Leonel de Oliveira

Revisão de inglês: Ananyr Porto Fajardo 